\section{REFERENCES}

1 Hansen JE, Sun X-G, Wasserman K. Should forced expiratory volume in six seconds replace forced vital capacity to detect airway obstruction? Eur Respir J 2006; 27: 1244-1250.

2 Hansen JE, Sun XG, Wasserman K. Discriminating measures and normal values for expiratory obstruction. Chest 2006; 129: 369-377.

3 Enright P. Does screening for COPD by primary care physicians have potential to cause more harm than good? Chest 2006; 129: 833-834.

4 Pellegrino R, Viegi G, Brusasco V, et al. Interpretative strategies for lung function tests. Eur Respir J 2005; 26: 948-968.

5 Enright P. Flawed interpretative strategies for lung function tests harm patients. Eur Respir J 2006; 27: 1322-1323.
6 Pelligrino R, Brusasco V, Crapo RO, et al. Flawed interpretative strategies for lung function tests harm patients. Eur Respir J 2006; 27: 1323-1324.

7 Crapo RO, Morris AH, Gardner RM. Reference spirometric values using techniques and equipment that meet ATS standards. Am Rev Respir Dis 1981; 123: 659-664.

8 Knudson RJ, Lebowitz MD, Holberg J, Burrows B. Changes in the normal maximal expiratory flow-volume cure with growth and aging. Am Rev Respir Dis 1983; 127: 725-734.

9 Hankinson JL, Odencrantz JR, Fedan KB. Spirometric reference values from asample of the general US population. Am Rev Respir Crit Care Med 1999:159:179 187.

DOI: 10.1183/09031936.00112706

\title{
Epidemiology and costs of COPD
}

\section{To the Editors:}

The lead article in the series "The global burden of chronic obstructive pulmonary disease", on the epidemiology and costs of COPD, touched briefly on the subject of occupational factors in the section on "tobacco and other causes" of the disease [1]. One of the four citations noted in that discussion was in reference to a report on smoking, occupational and demographic characteristics in a population-based sample of $>1,000$ elderly Finns, carried out in 1990-1991 [2]. This study was cited to support the following statement: "It is likely that the interaction between occupational exposure and other risk factors determines whether an individual develops COPD." [2]

Having served on the American Thoracic Society (ATS) task force that developed a recent statement on the occupational contribution to the burden of airway disease [3], which was also cited in the European Respiratory Journal article, we were intrigued by the Finnish study, since it had not come up in our task force's review and appeared to be potentially relevant. We subsequently read the study closely. It does include descriptive data on smoking, social class and occupational dust exposure, but it presents no formal statistical testing of the association between occupational dust and chronic obstructive pulmonary disease (COPD).

As the tabular data in the published paper [2] allowed categorisation of all subjects with respect to airflow obstruction (forced expiratory volume in one second $\leqslant 65 \%$ predicted, the study definition of COPD), sex, occupational dust exposure, social class (lowest versus middle and higher combined), and smoking status (ever versus never), we were able to recreate the data set (limited to these variables) for the purposes of risk modelling.

Occupational dust exposure and lower social class were interrelated $(p=0.02)$. In a multiple logistic regression model adjusting for sex and smoking and including three dust-social class exposure variables (dust and low social class (25\%), dust and higher social class (50\%), and lower social class without dust $(7 \%))$, combined dust and lower social class was associated with a significantly increased risk of obstruction (odds ratio 2.3; 95\% confidence interval 1.1-4.8). Neither dust exposure among those of higher social class, nor lower social class without reported dust exposure was a statistically significant risk factor for airflow obstruction in the same model. Out of 82 cases among 1,191 observations, 28 (34\%) fell into the lower class-work dust risk category, yielding a population-attributable risk percentage estimated to be $19.6 \%$.

IsOAHO et al. [2] acknowledge that their definition of COPD subsumes asthma. Indeed, 20 of the 82 subjects defined in the study as having COPD on the basis of airflow obstruction also had clinical histories of asthma (two with work-related disease).Thus, the re-analysis we report may overestimate the risk of COPD due to dust, to the extent that asthma is even more strongly related to this factor than is COPD. The recent ATS estimate, however, suggests that the occupational burden of both COPD and asthma is similar among adults [3].

Regarding the reference to the Finnish study [2] in the European Respiratory Journal, this re-analysis could support the presence of an interaction between occupational dust exposure and social class, or the findings may simply reflect the differing types and amount of dust exposure inherent in job duties and occupations that are linked to categorisation by social class.

\section{P.D. Blanc and J.R. Balmes}

Division of Occupational and Environmental Medicine, Dept of Medicine, University of California, San Francisco, CA, USA.

\section{REFERENCES}

1 Chapman KR, Mannino DM, Soriano JB, et al. Epidemiology and costs of chronic obstructive pulmonary disease. Eur Respir J 2006; 27: 188-207.

2 Isoaho R, Puolijoki H, Huhti E, Kivela S-L, Laippala P, Tala E. Prevalence of chronic obstructive pulmonary disease in elderly Finns. Respir Med 1994; 88: 571-580.

3 Balmes J, Becklake M, Blanc P, et al. American Thoracic Society statement: occupational contribution to the burden of airway disease. Am J Respir Crit Care Med 2003; 167: 787-797.

DOI: $10.1183 / 09031936.00097406$ 